\title{
Genetic and Environmental Effects on Water Use Efficiency in Peach
}

\author{
D. Michael Glenn ${ }^{1}$ and R. Scorza ${ }^{2}$ \\ USDA-ARS Appalachian Fruit Research Station, 2217 Wiltshire Road, Kearneysville, WV 25430-2771 \\ W.R. Okie ${ }^{2}$ \\ USDA-ARS Fruit and Tree Nut Research Laboratory, 21 Dunbar Road, Byron, GA 31008-1008
}

\begin{abstract}
AdDitional INDEX wORDs. isotopic carbon discrimination, peach breeding, Prunus persica, light interception, whole canopy gas exchange, lysimeter

Aвstract. Two unpruned narrow-leaf and two unpruned standard-leaf peach [Prunus persica (L.) Batsch.] selections were evaluated for physiological components related to water use efficiency \{WUE [carbon assimilation (A) per unit of transpiration (T)]\}. The purpose of the study was to assess the value of narrow-leaf phenotypes to improve WUE in peach and separate the environmental component of canopy geometry from the genetic components. The narrow-leaf characteristic itself did not confer improved WUE. The interception of light was a key determinant of WUE in these genotypes. Internal shading of the tree by excessive leaf area reduced daily WUE measured in gas exchange studies. Canopies that intercepted more than $75 \%$ of the photosynthetically active radiation $(P A R)$ had reduced daily WUE. Dormant season pruning of the four genotypes lowered isotopic carbon discrimination and therefore increased seasonal WUE compared to unpruned trees. None of the genotypes had a significant correlation of seasonal WUE with leaf and fruit weight. Analysis of covariance indicated that 'Bounty' and both narrow-leaf genotypes had greater leaf and fruit weight than 'Redhaven' for a given level of PAR interception. 'Bounty' had the least internal canopy shading of the four genotypes. Genetic differences in peach growth types can be selected for factors increasing WUE as well as increased productivity. Future work in peach breeding to improve WUE and productivity must take into consideration light interception, productivity, and WUE in an integrated manner to make real progress in the efficient use of water and light in the orchard environment.
\end{abstract}

Water use efficiency in plants is affected by environmental and genetic factors. In peach, genetic characteristics affecting WUE have been identified in rootstocks (Bongi et al., 1994) and scion (Glenn et al., 2000). Peach requires an ample supply of water in the soil and high water transport to maintain high transpiration (T) and leaf cooling (Glenn et al., 1988). If transpirational cooling is restricted by limited water transport, leaf water potential will decrease, closing stomates and reducing carbon dioxide transport into the leaf. Photosynthesis (A) increases rapidly with increasing light from sun flecks or direct irradiance and is initially limited by stomatal conductance. However, a large vapor pressure gradient develops between leaf and air under irradiance, leading to high $\mathrm{T}$ and water stress that subsequently reduces stomatal conductance and A. Wilting of immature leaves and developing shoots at midday is common under even well-watered conditions (personal observations). Tenhuen et al. (1982) demonstrated that high transpirational demand can induce midday stomatal closure despite adequate water availability

In analyzing the components of WUE, certain parameters indicate the potential for manipulation to increase WUE (Nilsen and Orcutt, 1994):

$$
\text { WUE }=\frac{\mathrm{A}}{\mathrm{T}} \frac{\mathrm{dt}}{\mathrm{dt}}=\frac{(1-\Phi)(\mathrm{Ca}-\mathrm{Ci})}{1.6 \Delta \mathrm{w}}
$$

where $\mathrm{A}$ is net carbon assimilation from air; $\mathrm{T}$ is transpiration; $\Phi$ is the proportion of fixed carbon lost to respiration; $\mathrm{Ca}-\mathrm{Ci}$ is the partial pressure gradient of carbon dioxide from intercellular space to ambient air; $\Delta \mathrm{w}$ is the mean vapor pressure gradient from

Received for publication 29 Mar. 2005. Accepted for publication 21 Sept. 2005. 1 Research Soil Scientist; to whom requests for reprints should be addressed; e-mail address: mglenn@afrs.ars.usda.gov

${ }^{2}$ Research Horticulturist. intercellular space to ambient air; and 1.6 is the ratio of carbon dioxide to water diffusivity.

Genetic changes to the respiratory pathway can alter $\Phi$ to reduce respiration losses, and genetic changes can alter stomatal morphology to change $\mathrm{Ca}-\mathrm{Ci}$ and $\Delta \mathrm{w}$. Increasing $\mathrm{Ca}-\mathrm{Ci}$ and reducing $\Delta \mathrm{w}$ will increase WUE. Similarly, cultural and environmental changes can also alter the same components of WUE. Reducing plant temperature through shade netting, evaporative cooling, and reflectants will reduce $\Phi$ and generally increase stomatal conductance that increases $\mathrm{Ca}-\mathrm{Ci}$ while reducing $\Delta \mathrm{w}$. The ratio of carbon dioxide to water diffusivity (1.6) is an unchangeable, physical relationship.

Glenn et al. (2000) identified increased WUE in a narrow-leaf, chimeric, peach mutation compared to standard-leaf populations in growth chamber, greenhouse, and field studies. Carbon isotopic discrimination $(\Delta)$ studies of peach seedling populations with narrow leaves also had increased seasonal water use efficiency compared to standard-leaf populations. Two narrow-leaf selections from this breeding population were selected for further study as mature trees. The purpose of the present study was to assess the value of narrow-leaf phenotypes to improve WUE in peach and separate the potential environmental component of canopy geometry from the genetic components.

\section{Methods and Materials}

Two narrow-leaf phenotypes were selected, 'BY96P3889'(NL 89) and 'BY96P3494' (NL 94). The pedigree of the narrow-leaf phenotypes was 'Blazeprince' X 'BY92P2932' ('BY92P2932' = $\mathrm{F}_{3}$ of 'Flavortop' $x$ 'Fla.WL-1') (Okie and Scorza, 1992). 'Redhaven' and 'Bounty' peach were used as standard-leaf controls. All scions were grafted on 'BY520-9' rootstock ('Guardian' 
brand; South Carolina Agricultural Experiment Station, Clemson University, Clemson). The narrow-leaf phenotypes had narrower $(1.8 \mathrm{vs} .2 .9 \mathrm{~cm})$ and shorter $(9.9$ vs. $10.9 \mathrm{~cm})$ leaves compared to the controls. Stomatal density and aperature were measured as described by Glenn et al. (2000). Stomatal aperture was similar for all four genotypes $(28 \mu \mathrm{m})$ and stomatal density was not different for standard and narrow-leaf phenotypes (352 vs. 420 stomata $/ \mathrm{mm}^{2}$, respectively).

All genotypes were planted in 2001 at the U.S. Department of Agriculture Appalachian Fruit Research Station, Kearneysville, W.Va. Trees were planted $4 \mathrm{~m}$ apart within rows and $5 \mathrm{~m}$ between rows with grass drive strips between rows. The trees received standard disease and insect control during each growing season. Genotypes were planted in a completely randomized design with eight single-tree replications. Fruit were thinned to about $10 \mathrm{~cm}$ between fruit at the time of shuck split. In 2003 half of each phenotype were pruned to an open center structure $(n=4)$ in the dormant season and the same trees were pruned in 2004. Pruning was randomly assigned.

Whole canopy gas exchange was measured on 5 June, 24 July, and 11 Sept. 2003 on unpruned trees. Whole canopy gas exchange was measured by enclosing individual trees in mylar cuvettes as described in Glenn et al. (2003). A and T were measured from sunrise to sunset on each date for two randomly selected trees of each unpruned phenotype. Daily WUE was calculated as the quotient of A/T. Canopy light interception of the tree was measured using a 1-m quantum line sensor (model LI-191SA; LI-COR, Lincoln, Nebr.). One quantum line sensor was located in an unshaded area and used as a reference while a second was sequentially placed at eight regularly spaced points below the canopy and within the shaded area \pm 1 h of solar noon. Canopy light interception was calculated as the quotient of the shaded reading divided by the reference at the same time subtracted from 1, and the product expressed as a percentage. Following the whole canopy gas exchange measurements of 24 July, light sensor clusters were installed in the center of each tree to measure diurnal light levels within the canopy for a 3-d period. The light sensors were constructed of light-sensitive silicon chips (GaAsP G2711-01; Hammamatsu Corp., Bridgewater, N.J.). The sensors were attached to a metal pole at 1-, 2-, and 3-m heights from the soil surface and oriented south to eliminate shade from the pole. Four silicon sensors were clustered at each height. Two sensors were horizontally oriented: one upward, one downward. Two sensors were vertically oriented on opposite sides of the cluster facing east and west, respectively. All four sensors were wired in series so that the sum of their output (millivolts) was measured by the datalogger. Data were collected as a 10-min average and then an hourly and daily sum calculated for data analysis. Daily light interception was calculated as the quotient of mean daily incoming light at 1 and $2 \mathrm{~m}$ divided by the incoming light of the unshaded sensor above the canopy at $3 \mathrm{~m}$, subtracted from 1 , and expressed as a percentage.

At the end of the growing season, all leaves from each tree were collected by enclosing the tree in a net to contain the leaves. A subsample of leaves was collected from each tree and the leaf area measured on the fresh material. The dry weight of the subsample and the entire sample was measured after heating at $70{ }^{\circ} \mathrm{C}$ and weight was constant. Total leaf area was calculated by measuring the leaf area of approximately $200 \mathrm{~g}$ of oven-dried leaves and calculating the ratio between leaf weight and leaf area. The total mass of oven-dried leaves was then multiplied by this conversion factor. An individual conversion factor was calculated for each tree. When fruit were mature, all fruit were harvested and weighed. 'Redhaven' was harvested on 31 July, NL94 on 4 Aug., NL89 on 5 Aug., and 'Bounty' on 7 Aug. Yield was the sum of leaf and fruit weight. In 2004 no yield or PAR interception data were collected from the study area.

In 2002 a single tree of each genotype was excavated from field plots and placed in a wooden container during the dormant season. The tree root volume was initially excavated as a $1.5 \times 1.5 \times 1.5$ $m$ cube and placed into the container, which was slightly larger in all dimensions. Each tree was sequentially placed on a paired weighing lysimeter and T measured for a single day in 2003 with clear sky conditions. When on the lysimeter, a plastic covering over the top of the container prevented water loss from the soil. The 'Redhaven' tree was used as a reference of comparison and all other tree $\mathrm{T}$ rates were compared to the same 'Redhaven' $\mathrm{T}$ rate, providing three measurement days in total.

The terminal $30 \mathrm{~cm}$ of annual shoot growth was collected from unpruned trees in both the replicated field study and the lysimeter study. Ten shoots per tree were collected in the dormant season following the 2003 growing period. In 2004, a similar sampling protocol was used for unpruned and pruned trees. All buds were removed and the tissue analyzed for carbon-13 content (Isotopic Services, Los Alamos, N.M.). The isotopic discrimination value was calculated according to Farquhar et al. (1989) and used as a measure of seasonal WUE. The isotopic composition of carbon dioxide in air was assumed to be $-7.8 \mathrm{~mL} \cdot \mathrm{L}^{-1}$ (Francey et al., 1995).

Data were analyzed using regression analysis by genotype, with differences in the slopes and intercepts tested at $P=0.05$. When no differences in genotypes were indicated, the data were pooled for an overall regression relationship.

The genotype yield response was refined with analysis of covariance to utilize the interception of $P A R$ as an independent, quantitative factor in the analysis since biomass accumulation is directly related to $P A R$ interception. Analysis of covariance estimates the mean yield response of each genotype for the mean level of PAR interception averaged over all genotypes. Yield was analyzed using analysis of covariance in a completely randomized design using SAS. Adjusted genotype means were compared using least squares means from the analysis of covariance. Genotype means were compared using Fisher's protected least significant difference (LSD).

\section{Results and Discussion}

On the three sampling dates, there were significant differences between sampling date $(P=0.05)$ in $\mathrm{A}$, T, and WUE (Table 1$)$. Neither the individual genotype or leaf-shape phenotype significantly affected gas exchange on a whole canopy basis. A and T were greatest in July and least in September. WUE was greatest in June and least in July. These data indicate that the narrow-leaf characteristic itself did not confer improved daily WUE. The characteristic of high daily WUE in the early morning and late afternoon indicates that peach exhibits an avoidance strategy in which stomatal control is the dominant control mechanism of gas exchange, which may be driven by high temperature, increased vapor pressure deficit, and/or reduced mesophyll conductance, but not light (Fig. 1). The interception of light, however, is a key determinant of WUE in these genotypes. The relationship of daily WUE with intercepted $P A R$ by the entire canopy indicates a significant curvilinear relationship (Fig. 2) with no genotype effect. These data suggest that internal shading of the tree by excessive 
Table 1. Whole canopy gas exchange and water use efficiency of two peach-leaf phenotypes on three dates in 2003.

\begin{tabular}{lcccc}
\hline Peach-leaf & Date & $\begin{array}{c}\text { Carbon } \\
\text { dioxide } \\
\text { assimilation } \\
\left(\mathrm{mmol} \cdot \mathrm{m}^{-2} \cdot \mathrm{h}^{-1}\right)\end{array}$ & $\begin{array}{c}\text { Transpiration } \\
\left(\mathrm{mol} \cdot \mathrm{m}^{-2} \cdot \mathrm{h}^{-1}\right)\end{array}$ & $\begin{array}{c}\text { Water use } \\
\text { efficiency } \\
\left(\mathrm{CO}_{2} / \mathrm{H}_{2} \mathrm{O}\right) \\
\left(\mathrm{mmol} \cdot \mathrm{mol}^{-1}\right)\end{array}$ \\
\hline Standard & 5 June & 16.7 & 4.3 & 4.0 \\
Narrow & 5 June & 16.8 & 4.4 & 3.9 \\
Standard & 24 July & 21.8 & 7.6 & 3.0 \\
Narrow & 24 July & 22.5 & 8.1 & 2.9 \\
Standard & 11 Sept. & 12.2 & 3.8 & 3.3 \\
Narrow & 11 Sept. & 9.8 & 2.8 & 3.6 \\
\hline
\end{tabular}

zThere were significant difference $(P=0.05)$ between each date of sampling. Data are the mean of hourly values from 1000 to $1800 \mathrm{HR}$ for two genotypes and duplicate replications.

leaf area reduces daily WUE in canopies that intercept more than $75 \%$ of the PAR. Unpruned trees were used in the study to evaluate the plant habit in association with the leaf shape. Seasonal WUE is negatively correlated with $\Delta$ (Bacon, 2004; Bongi et al., 1994; Condon et al., 1990; Glenn et al., 2000; Jones, 2004). $\Delta$ increased and hence seasonal WUE decreased with increasing PAR interception and there was no genotypic effect (Fig. 3, top).

The lysimeter study clarifies this relationship. In the lysimeter study, $\mathrm{T}\left(\mathrm{kg} \cdot \mathrm{m}^{-2}\right.$ leaf area per day) of each genotype was compared to T of the standard, 'Redhaven'. T of 'Redhaven' varied little for the $3 \mathrm{~d}$ of measurement (Fig. 3, middle) and $\mathrm{T}$ of the four genotypes declined with increasing $P A R$ interception. Seasonal WUE (as related to $\Delta$ ) increased as T increased (Fig. 3, bottom) in the lysimeter study. Increased canopy interception of PAR by the lysimeter trees also reduced seasonal WUE (Fig 3, top). The difference between the lysimeter trees and the field-grown trees (Fig. 3 top) is likely due to the removal of a portion of the root zone and restriction of the root zone by the container with the lysimeter trees. The internal shading that occurs as PAR interception increases, reduces WUE by limiting the radiant energy to the leaves that drives T, A, and leaf cooling, particularly in leaves within the canopy.

Analysis of covariance was used to estimate the mean response (yield) for each genotype averaged over the intercepted $P A R$. Intercepted $P A R$ was a significant $(P=0.05)$ covariate for all genotypes. 'Bounty' and both narrow-leaf genotypes had greater yield than 'Redhaven' (Table 2). However, there was

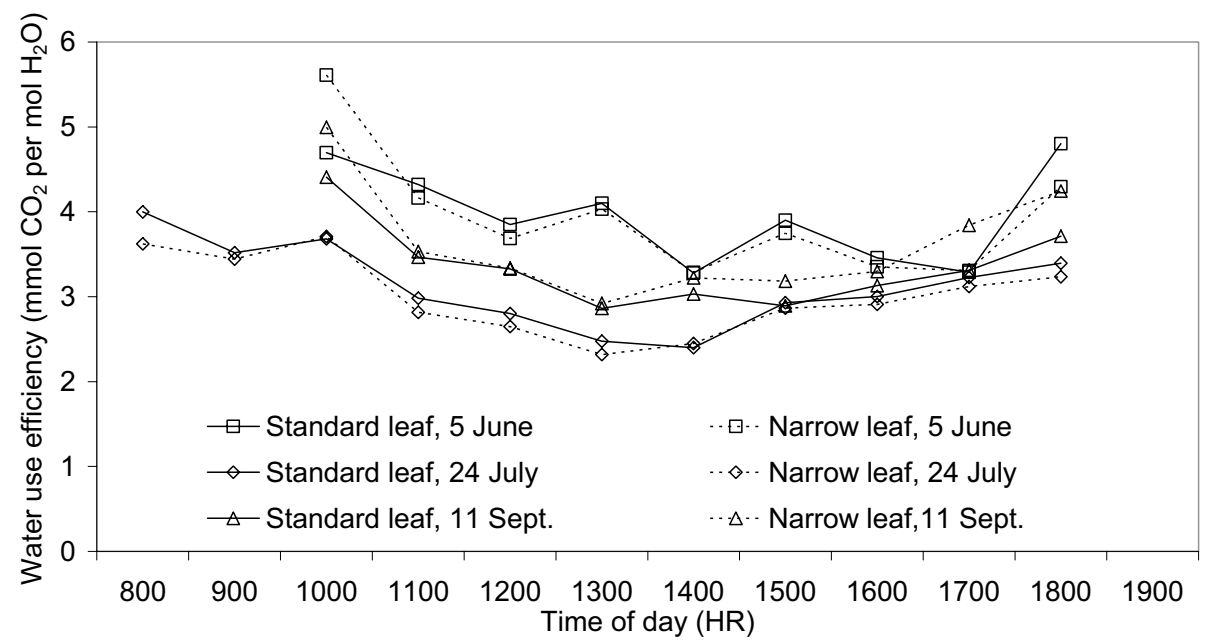

Fig. 1. Daily water use efficiency of standard-leaf and narrow-leaf peach phenotypes on three dates in 2003 from whole canopy gas exchange chambers.

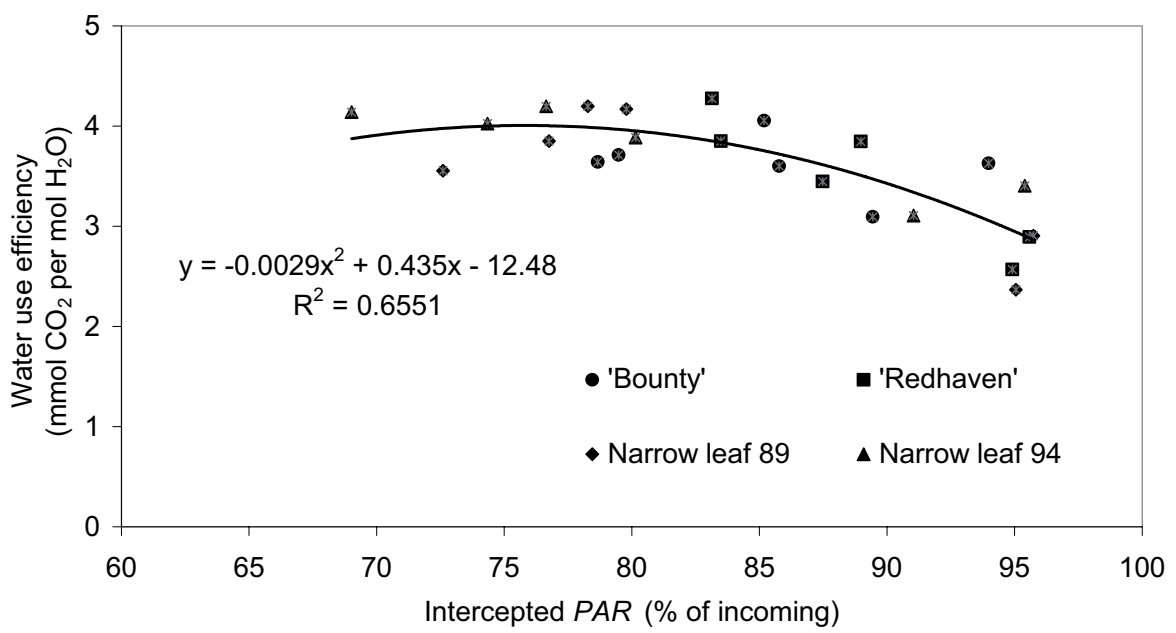

Fig. 2. Relationship between intercepted photosynthetically active radiation $(P A R)$ and daily water use efficiency in 2003 for four peach genotypes from whole canopy gas exchange chambers. 

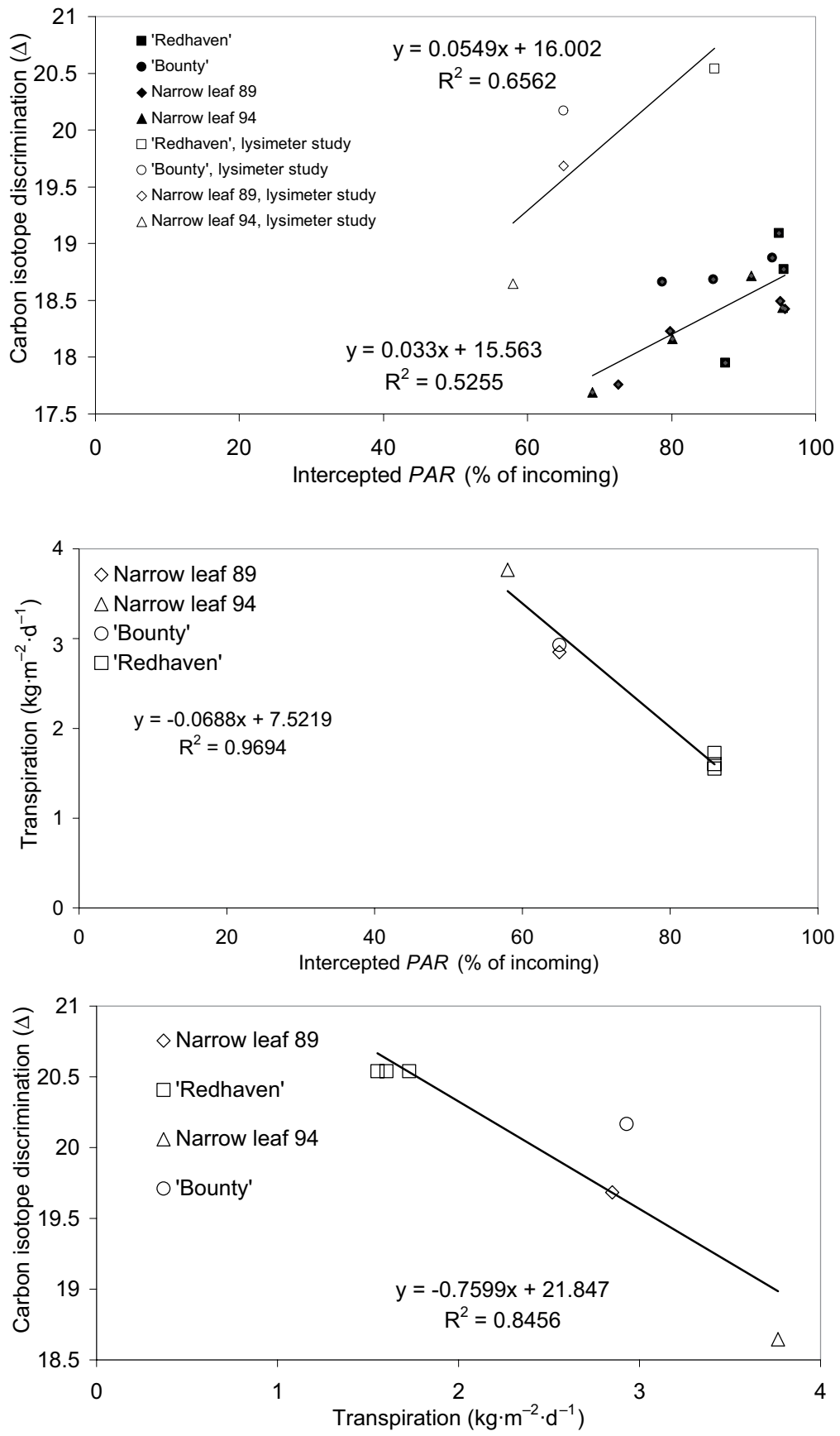

Fig. 3. The relationship of midday intercepted photosynthetically active radiation $(P A R)$ with carbon isotopic discrimination (top), and transpiration (middle), and the relationship of carbon isotopic discrimination with transpiration (bottom) for four peach genotypes from whole canopy gas exchange chambers and trees measured on weighing lysimeters.

no significant relationship between $\Delta$ and yield for any genotype (data not presented).

It has been generally demonstrated that increased WUE is related to decreased productivity (Jones, 2004) due to the action of stomatal closure that limits carbon dioxide diffusion into the leaf more than it limits water diffusion out of the leaf. We have demonstrated, however, that 'Bounty' and the narrow-leaf phenotypes have improved productivity without reduced WUE compared to 'Redhaven'.

Whole canopy gas exchange studies only measure daily WUE, and carbon isotope discrimination is not affected by respiratory loss of carbon $(\Phi)$ nor does it indicate if the change in seasonal WUE is due to changes
Table 2. Yield of four peach genotypes in 2003 using photosynthetically active radiation $(P A R)$ as the covariate.

\begin{tabular}{llc}
\hline Genotype & $\begin{array}{c}\text { Yieldz } \\
\left(\mathrm{kg} / \text { tree }^{\mathrm{C}}\right)\end{array}$ & $\begin{array}{c}\text { Adjusted yieldy } \\
(\mathrm{kg} / \text { tree })\end{array}$ \\
\hline 'Bounty' & $46.1 \mathrm{~A}$ & $46.2 \mathrm{~A}$ \\
Narrow leaf 84 & $39.8 \mathrm{AB}$ & $40.6 \mathrm{~A}$ \\
Narrow leaf 91 & $37.5 \mathrm{AB}$ & $39.6 \mathrm{~A}$ \\
'Redhaven' & $30.8 \mathrm{~B}$ & $27.9 \mathrm{~B}$
\end{tabular}

${ }^{2}$ Mean separation using Fisher's protected least significant difference $(P=0.05)$.

yndicates a significant difference $(P=0.05)$ based on analysis of covariance using $P A R$ interception as the covariate. Values are adjusted means based on the mean PAR interception.

in the photosynthetic pathway or stomatal conductance linkage to the environment (Nilsen and Orcutt, 1994). However, there is an indication that canopy structure is a key component of increased WUE in this peach study. 'Bounty' had greater light interception at both 1- and 2-m heights within the center of the canopy, compared with 'Redhaven' (Fig. 4). Increased light in the canopy interior would likely increase stomatal conductance, leaf cooling, and gas exchange. Increasing light distribution within the canopy of fruit trees is an established horticultural priority to improve fruit color and increase fruit bud initiation and overall productivity (Ferree, 1989; Heinicke, 1966; Marini et al., 1991; Morgan et al., 1984). It appears that the horticultural practices associated with "opening" a canopy also increase WUE. In 2004, pruned genotypes had a lower $\Delta$ than unpruned genotypes (17.67 vs. $18.16, P<0.05)$ across all genotypes and hence a higher seasonal WUE than unpruned genotypes due to increased PAR penetration of the canopy. There was not a significant pruning $x$ genotype interaction in 2004 for $\Delta$. In 2004, 'Redhaven' had higher $\Delta$ than 'Bounty', NL 89, or NL 94 (19.00 vs. $17.69,17.51$, and 17.47 , respectively, and pooled over pruned and unpruned trees, $P<0.05$ ), contrary to our 2003 findings, in which no difference was found. These data indicate a lower seasonal WUE of 'Redhaven' compared to the other genotypes in 2004 in addition to the lowest 2003 yield (Table 2). Increasing light distribution within tree canopies can be accomplished with both genetic and cultural techniques.

The narrow-leaf peach was initially chosen for this work on the hypothesis that smaller, narrower leaves would aid in light penetration into the canopy interior; however, light penetration studies (Fig. 4) did not support this hypothesis and there was not an improvement in WUE due only to narrow-leaf phenotypes (Figs. 2 and 3). Our earlier work with potted narrow-leaf peach did not examine canopy structure (Glenn et al. 2000). Productivity of both narrow-leaf genotypes was an improvement over 'Redhaven' (Table 2). The 7-d range of harvest dates was not considered to be a significant bias in productivity. There still needs to be further evaluation of the pruned narrow-leaf peach growth type because the smaller leaves may aid light penetration with minimal pruning, since standard dormant season pruning in this study has demonstrated improvement in seasonal WUE.

Future work in peach breeding to improve WUE 

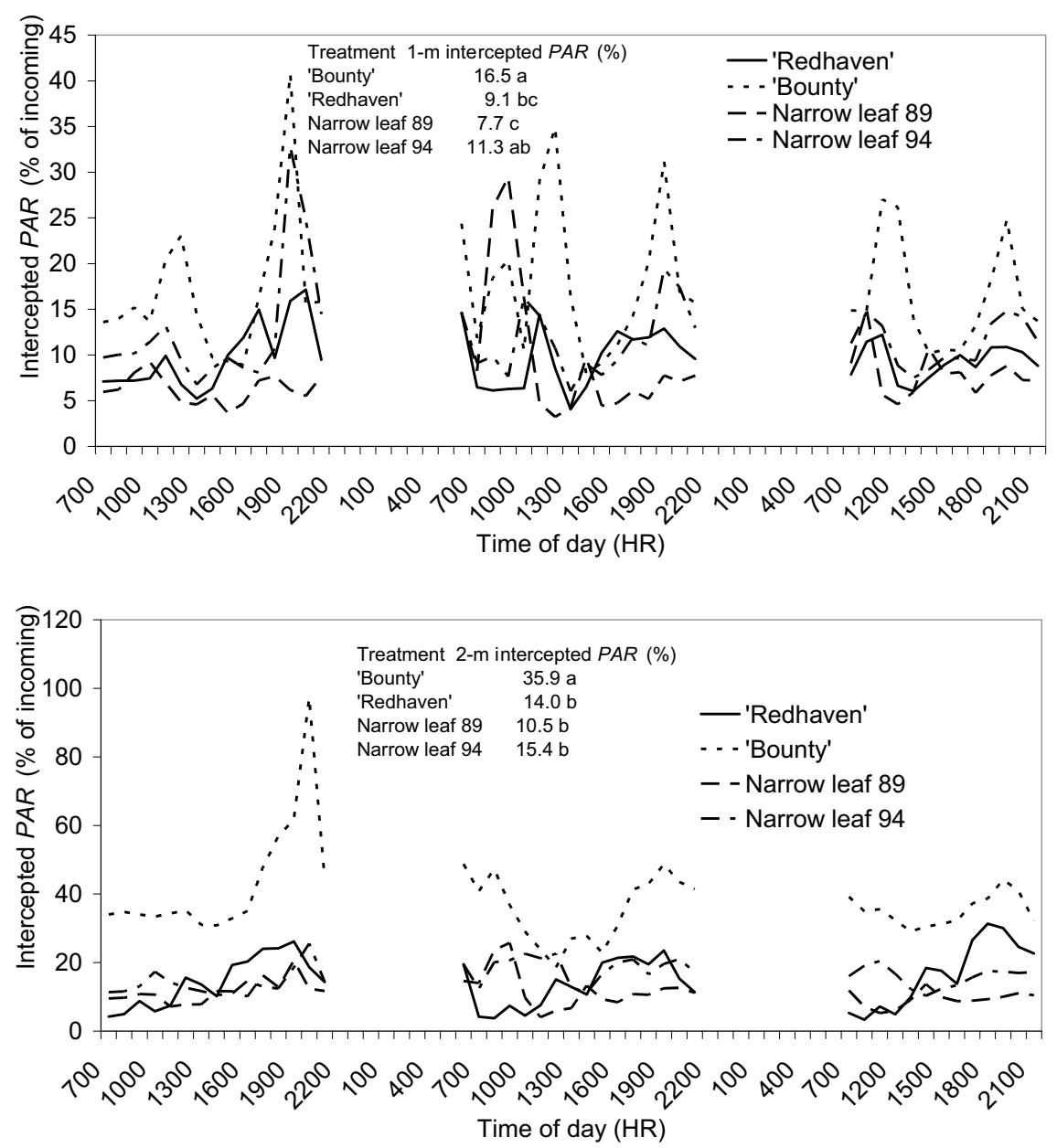

Fig. 4. Intercepted photosynthetically active radiation $(P A R)$ in four, unpruned peach genotypes at 1-m (top) and 2-m (bottom) heights in the center of the canopy from field-grown trees.

and productivity must take into consideration light interception, productivity, and WUE in an integrated manner to make real progress in the efficient use of water and light in the orchard environment, in addition to identifying the mechanisms that are responsible.

\section{Literature Cited}

Bacon, M.A. 2004. Water use efficiency in plant biology, p. 1-22. In: M.A. Bacon (ed.). Water use efficiency in plant biology. CRC Press, Boca Raton, Fla.

Bongi, G., A. Palliotti, P. Rocchi, and G. Roselli. 1994. Evaluation of WUE in peach grafted on different interspecific hybrid rootstocks. Plant Physiol. Biochem. 32:149-157.

Condon, A.G., G.D. Farquhar, and R.A. Richards. 1990. Genotypic variation in carbon-isotope discrimination and transpiration efficiency in wheat: Leaf gas exchange and whole plant studies. Austral. J. Plant Physiol. 17:9-22.

Farquhar, G.D., J.R. Ehleringer, and K.T. Hubick. 1989. Carbon isotope discrimination and photosynthesis. Annu. Rev. Plant Physiol. Mol. Biol. 40:503-537.

Ferree, D.C. 1989. Influence of orchard management systems on spur quality, light, and fruit with the canopy of 'Golden Delicious' apple trees. J. Amer. Soc. Hort Sci. 114:869-875.

Francey, U.J., P.P. Tans, C.E. Allison, I.G. Enting, J.W.C. White, and M. Troller. 1995. Changes in oceanic and terrestrial carbon uptake since 1982. Nature 373:326-330.

Glenn, D.M., A. Erez, G. J. Puterka, P. Gundrum. 2003. Particle films affect carbon assimilation and yield in 'Empire' apple. J. Amer. Soc. Hort. Sci. 128:356-362.

Glenn, D.M., R. Scorza, and C. Bassett. 2000. Physiological and morphological traits associated with increased water use efficiency in the narrow-leaf peach. HortScience 35:1241-1243.

Glenn, D.M. Worthington, J.W. Welker, W.V. and McFarland, M.J. 1988. Estimation of peach tree water use using infrared thermometry. J. Amer. Soc. Hort. Sci. 114(5):737-741.

Heinicke, D.R. 1966. Characteristics of 'McIntosh' and 'Red Delicious' apples as influenced by exposure to sunlight during the growing season. Proc. Amer. Soc. Hort. Sci. 89:10-13.

Jones, H. 2004. What is water use efficiency?, p. 27-40. In: M.A. Bacon (ed.). Water use efficiency in plant biology. CRC Press, Boca Raton, Fla.

Marini, R.P., D. Sowers, and M.C. Marini. 1991. Peach fruit quality is affected by shade during final swell of fruit growth. J. Amer. Soc. Hort. Sci. 116:383-389.

Morgan, D.C., C.J. Stanley, R. Volz, and S.I.J. Warrington. 1984. Summer pruning of 'Gala' apple: The relationship between pruning time, radiation penetration, and fruit quality. J. Amer. Soc. Hort. Sci. 109:637-642.

Nilsen, E.T. and D. M. Orcutt. 1994. The physiology of plants under stress-abiotic factors. Wiley, New York.

Okie, W.R. and R. Scorza. 1992. Breeding peach for narrow leaf width. Acta Hort. 592:137-141.

Tenhuen, J.D., O.L. Lange, and D. Jahner. 1982. The control by atmospheric factors and water stress of midday stomatal closure in Arbutus unedo growing in a natural macchia. Oecologia 55:165-169. 